\title{
Notas Sobre a Subjetividade em Nossos Tempos
}

Pretende-se discutir neste trabalho algumas questões da pós-modernidade que permeiam a constituição e organização das formas de subjetividade, a partir da experiência clínica, institucional e docente dos autores. Elementos sociais e culturais, tais como o crescente uso de computadores, a globalização, a comunicação à distância, as redes digitais e a virtualidade, parecem estar produzindo efeitos no campo subjetivo, que indicam transformações nos referenciais de tempo e espaço: uma desterritorialização dos corpos e das relações entre os indivíduos. Pontua-se o lugar da Psicologia neste momento histórico vislumbrando, portanto, novas organizações subjetivas.

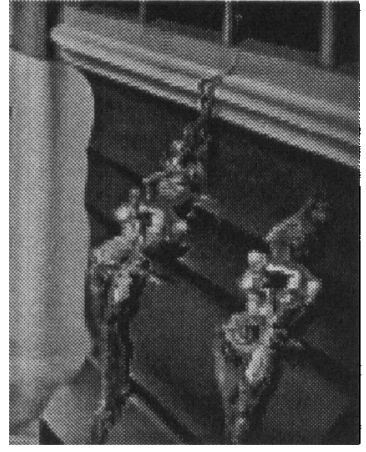

Fernando Carlos Santaella Megale Psicanalisto, mestree doutorando em Pslcologia Escolar pelo Instituto de Psicologia da USP Apoio Cnpq

Jurema Teixeira - Mestre em Psicologia Clínica pela PUC/SP e doutoranda em Cléncias Socials pela PUC/SP Apoio Cnpq

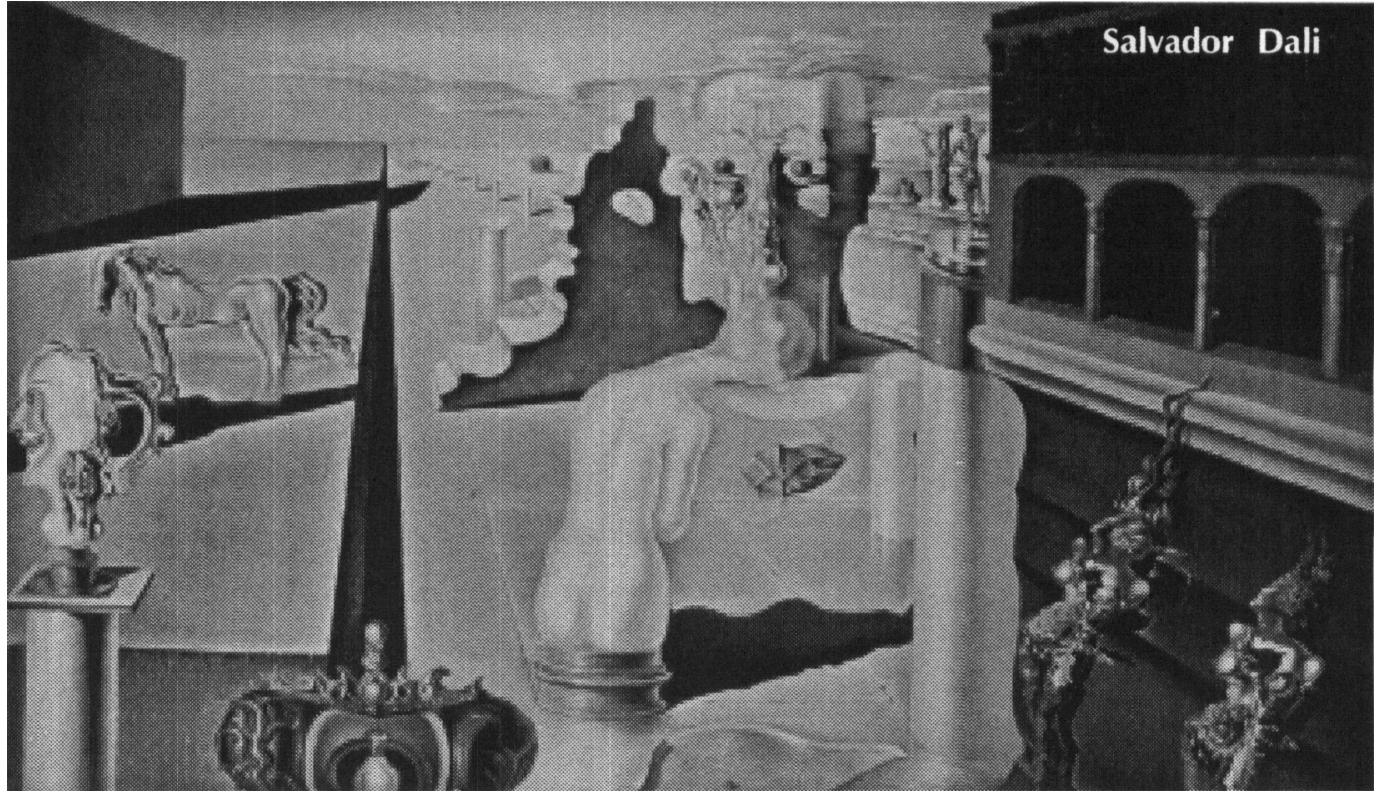

Este trabalho tem como objetivo delinear algumas questōes que nos mobiliza a prática clínica, institucional e docente, em tempos pós-modernos e abaixo do Equador, ou seja, tempo de globalização por um lado, e pouco desenvolvimento por outro. Tempo este, marcado pela questão da comunicação à distância e do uso da internet, que certamente produzem efeitos sobre a construção da subjetividade dos indivíduos e, em um movimento conjunto, tempo de questionamento dos referenciais sociais e, sobretudo, dos objetivos sociais em torno dos quais uma sociedade está organizada.

Ora, o que queremos dizer é que vivemos um certo mal-estar, pois por um lado há uma certa pulverização da noção de identidade e por outro, uma cristalização de uma referência identitária, uma pressāo de que nāo precisamos dos outros, isto é, cada um, sozinho, em seu mundo, pode buscar seus próprios referenciais ordenadores de seu cotidiano e de seus desejos, criando, portanto, uma sociedade tipicamente feita de perfispadrão, kits-comportamento que insistem em serem consumidos independentes do contexto que se encontram. O que encontramos e o que vemos se produzir é um tipo de subjetividade ilusoriamente marcada por uma individualidade, isto é, o 
que caracteriza e distingue cada indivíduo é uma falsa roupagem que se compra através das peripécias do marketing e da propaganda. Isto, por si só, implica em uma identidade referenciada em enganos narcísicos, pois os indivíduos pretendem-se colocar como diferentes e acabam por se perder em horizontes ilusórios, no entanto, exige-se deles que se mostrem como extremamente inovadores e únicos em seus atributos e qualidades.

As formas de relação intersubjetiva que se produzem pelo advento da virtualidade entram neste contexto para ampliar a discussão. Ao mesmo tempo em que possibilitam uma comunicação e uma troca de informações entre pessoas de diferentes culturas, em um tempo antes nunca experimentado, o que provoca naturalmente um progresso em termos de educação, política e outros campos, por outro lado parecem constituir um novo ordenamento das relações entre os indivíduos, extremamente marcado por uma prevalência da imagem e por uma desnecessária participação dos indivíduos em efetivas relações, ou seja, implicados em um campo social mais amplo e na coletividade.

Guattari (1992), ao comentar sobre as redes digitais, aponta para uma desterritorialização dos corpos, na medida em que a virtualidade permite uma espécie de possibilidade infinita de comunicação que retira os indivíduos de seus corpos, suporte indispensável de uma subjetividade ancorada no campo social, e representante de referenciais sociais. A virtualidade permitiria uma espécie de mágica que retira do sujeito aquilo que lhe sustenta enquanto ser social e que se defronta com as impossibilidades da vida, um corpo marcado por seus limites e uma subjetividade marcada por um certo tempo e um certo espaço. Produtora e facilitadora de um ponto de vista, geradora de instabilidades por outro.

Portanto, nossas subjetividades são tomadas por dois processos: "o enrijecimento de identidades locais e a ameaça de pulverização total de toda e qualquer identidade"(Rolnik, 1997).
Como saída, aparecem os movimentos coletivos que compram alguns kits que estão à venda no mercado: as drogas-produto do narcotráfico; as drogas- da psiquiatria, as supervitaminas contra o stress; a TV; a literatura de auto-ajuda; as terapias alternativas; e as drogas diet/light. $\mathrm{O}$ afastamento dos indivíduos em relação a suas próprias questões, tanto de seu campo pessoal quanto de seu campo social, provoca este tipo de ação social onde algum saber externo vem para regrar a conduta de cada um, vem para normatizar os comportamentos. A possibilidade de consumo incide sobre um dever, um imperativo, na medida em que isto passa a ser indicativo dos sintomas sociais, e dos movimentos de exclusão: é imperativo possuir os objetos que o capitalismo nos apresenta sob um semblante de melhoria de qualidade de vida, portanto há aqueles que não podem Ter esse acesso e que, então, situam-se como marginalizados. Mesmo aos que podem vir a Ter, tal imperativo provoca uma espécie de impotência social, visto não haver a possibilidade ou mesmo o tempo para usufruir do que se possui.

Nossa subjetividade, como concebemos com tempo e espaço, parece está se perdendo e temos em seu lugar, vários vetores construídos por uma nova ordem mundial que abre novas instâncias individuais e/ou coletivas, emergindo novos territórios existenciais.

Se, por um lado é possível apontar elementos que destacam um inflacionamento de tudo que é da natureza do eu, do si mesmo, por outro lado a dimensão privada, da intimidade e do particular parece estar reduzida e sendo progressivamente invadida pelos fenômenos da chamada globalização, desconsiderando os limites da comunicação e, por vezes das diferenças. Nessa tensão entre kits-alienantes e perdas de fronteiras, produz-se uma certa organização social e subjetiva, para que não se viva uma vazio insuportável. Parece, como afirma Amaral (1997), mais uma tentativa “... de reconciliação forçada entre o indivíduo e a sociedade, entre o psiquismo individual e a totalidade social...". 
É nesse sentido que vemos Lacan (1956-1957) comentar a respeito da constituição imaginária do eu, delineando sua faceta de desconhecimento e alienação presente em suas certezas que se colocam por vezes ortopédicas e limitantes para o sujeito e para o desejo. Articula, neste caminho, o eu como um sintoma social, e o que vemos se produzir é toda uma concepção que contrapõe o eu ao sujeito do desejo, a igualdade igualitária à diferença subjetivante. $O$ desejo aparece a despeito da totalização do eu. Poderíamos, então, pensar que os fenômenos de globalização e desfronteiramento poderiam colaborar para uma des-coberta das diferenças e das particularidades de cada cultura, no entanto tudo indica mais um movimento no sentido de uma produção alienante e rigidificadora.

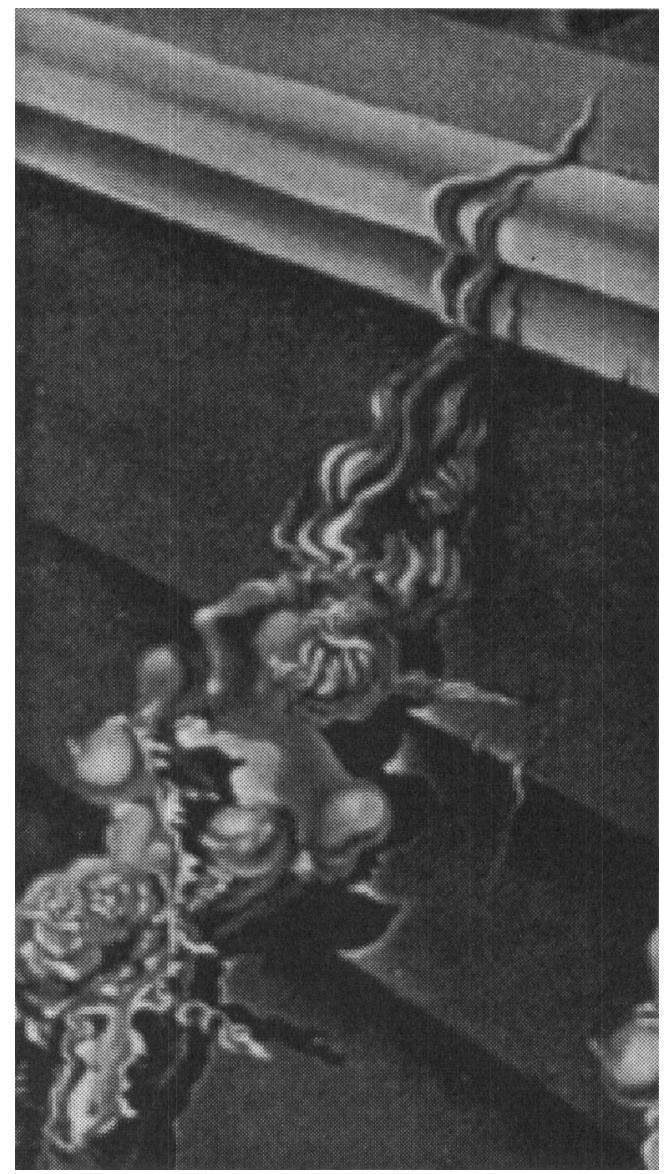

Hoje, os processos de subjetivação são fundamentalmente desconhecidos e descentrados do indivíduo, mas são fabricados no registro social, já que estamos imersos em uma sociedade marcada e constituída pela informática, pela comunicação à distância, pela invasão dos computadores em todos os espaços, desde os públicos até os privados. Os computadores e as redes digitais estão cada vez mais presentes em nosso cotidiano. Mais ainda, parece estar se delineando um caminho onde praticamente todas as questões e os fazeres da ordem pública poderão ser realizados na esfera do privado, determinando deste modo um certo tipo de relação entre os indivíduos, entre os indivíduos e os objetos. Isto quer dizer que talvez daqui a alguns anos não será preciso sair de casa e da frente da tela de seu computador para fazer uma série de atividades interrelacionais tais como trabalhar, estudar, ir ao cinema, conversar com amigos, ir a uma festa ou até mesmo fazer terapia ou análise etc., como já nos mostram algumas produções cinematográficas que, de forma estupenda, anunciam um futuro que já está no presente.

Isto é, o espaço público invade o espaço privado, contudo de uma certa maneira que desprende o seu próprio caráter de público, efeito das relações entre sujeitos diferentes, produção e debate de idéias e conceitos, de crenças e teorias, de semi-verdades. Trata-se mais de uma sobreposição que mantém o sujeito de olho em seu umbigo, de um falso movimento de produzir diferenças, da sustentação de um lugar estrutural que coloca o sujeito fora do cotidiano, fantasisticamente em uma posição de olhar o que se passa lá fora.

Neste caso, não se trata então de assumir uma posição do estilo "não tenho nada a ver com isso" ou "isto acabará com a ética " ou apocalípticas, posições assumidas por muitas vezes por psicólogos, elaborando críticas de teor fundamentado, entretanto sem levar em consideração que já estamos tomados pela sociedade da informática. Ou seja, uma postura que apenas indica críticas sem considerar que os mesmos críticos já se utilizam da tecnologia, nos parece ingênua $e$ 
destituída de sentido, ou mesmo um pouco retrógrada. Por outro lado, é função do saber psicológico e psicanalítico estudar os efeitos desta mudança na subjetividade dos indivíduos, sabendo desde já que estamos também dentro do que propomos criar. Não se trata de fazer propostas para interromper o que não há como se interromper, como se parássemos no tempo. Além disso, como afirma Souza (1991) quando discute a questão da psicanálise em intensão e da psicanálise em extensão, "Trata-se, sim, do voto de que o que possa ser obtido na psicanálise em intensão não se esgote no âmbito do indivíduo, caso em que uma análise se resumiria a aquisições pessoais que possibilitariam ao "analisado" um maior "jogo de cintura" dentro de uma sociedade inalterada pelo advento da psicanálise". É do campo ético estender estes limites, onde o campo individual e o campo social se cruzam, produzindo um só terreno de ação e reflexão.

A reflexão aproxima-se, neste sentido, de uma tentativa de avaliar e pensar nestes efeitos produzidos na subjetividade de todos nós, considerando que podemos estar diante de uma nova constituição de uma subjetividade. Os caminhos indicam movimentos que deslocam os referenciais da cultura e dos valores, do sujeito e de seus norteadores em sua vida. Sabemos que a noção de sujeito é essencialmente moderna e, como tal, historicamente datada e produzida nos últimos séculos. Sabemos também que, em outros tempos ( e não tão longe assim), a organização social passava muito menos pelas ações de um sujeito possuidor de uma subjetividade do que um campo social que, por si próprio, tomava conta dos destinos de cada um. Haja visto as consideraçōes fundamentais de Áries (1978) sobre a maneira como as crianças eram tratadas há 2 ou 3 séculos atrás. Não havia a estrutura de família tal como conhecemos, e as crianças eram arrebanhadas por um social que as constituía. $O$ mundo privado não era tão fundamental quanto é agora, a família não era considerada como a cerne do mundo social e psíquico, como concebido neste século por grande parte das teorias, inclusive por
Freud em sua concepção de desenvolvimento infantil e sexual. Então, a dimensão do privado é essencialmente uma questão do nosso século, esta preocupação e cuidado

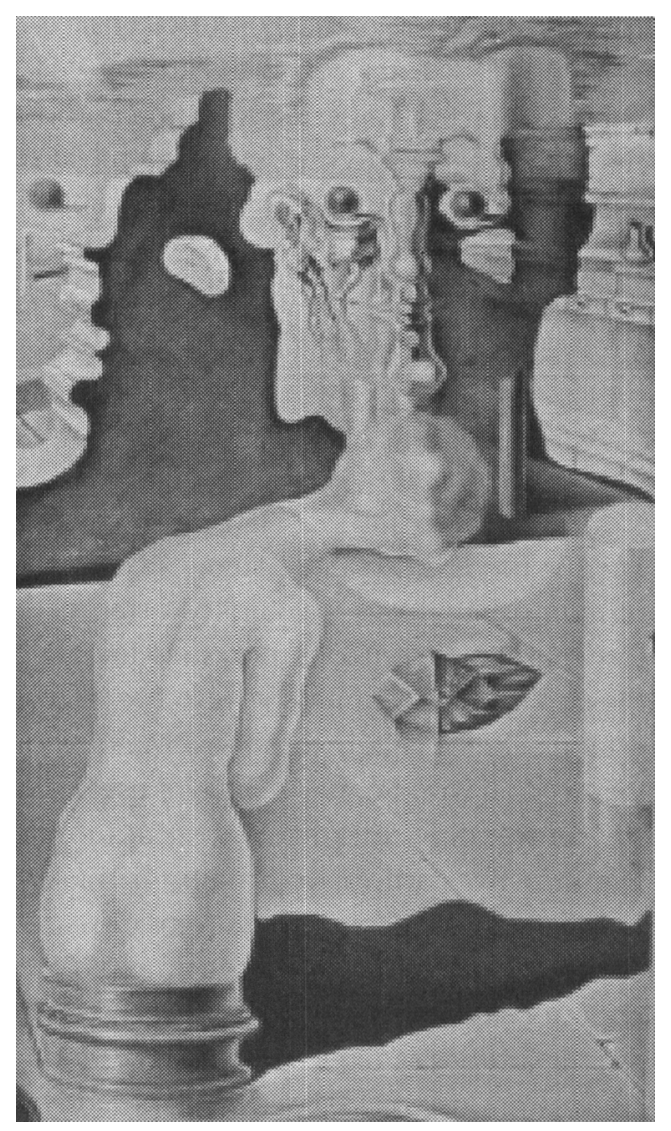

exagerado que temos com aquilo que se passa no seio de nossa família, com as relações que se estabelecem entre pais e filhos, com a educação, como se estes elementos fossem os únicos produtores de subjetividade em nós mesmos. Podemos até dizer que a própria Psicologia surgiu deste movimento, e contribuiu em muito com esta demarcação de território, inflando a dimensão do individual, das relaçōes domésticas, dos traumas que se passam na alcova das famílias.

O que queremos dizer é que, caso assumíssemos uma postura de nada quero saber disso, estaríamos também negando nossa temporalidade e a temporalidade de nossos conceitos e de nossas ações. Avançando um pouco mais, penso ser

\section{... a dimensāo do privado é essencialmente uma questão do nosso século.}


importante estarmos atentos a algo que parece ser a organização de um novo tipo de subjetividade, que já vemos se delinear nas crianças que mantemos contato em nossa prática. Prevalece as referências da ordem da imagem, em detrimento da ordem da palavra, o que por si só já nos deixaria falando horas e horas. A imagem parece se constituir como o centro deste novo tempo, o que já havia se anunciado pela introdução da televisão nos anos 50, ou pelo advento da propaganda nos últimos tempos. Entretanto, a questão vai além, pois a imagem parece coisificar o sujeito, as relações que se estabelecem, os desejos e o tempo, o que nos é impossível em nosso conceito de subjetividade.

Em que medida coisifica o sujeito? Bom, não há como negar que os sujeitos estão cada vez mais representados por suas imagens, mesmo quando falamos de relações que se estabelecem via internet, por exemplo, onde existe a palavra. Só que a palavra esvaziada de referência simbólica, absolutamente tomada no campo do imaginário, sem intervenção daquilo que Freud nos disse que seria o princípio de realidade, em contraposição ao princípio de prazer. Vamos refletir sobre isto: alguém poderia dizer que há a introdução da realidade, na medida em que estou supondo um desejo no outro que não sei, que desconheço. Contudo não nos debatemos na experiência com a hiância que é estabelecer relações concretas com os outros, hiância que revela e desvela nossa fragilidade e ignorância diante deste outro, $\mathrm{e}$ que promove conflitos. O outro, com seu corpo, com seu desejo, não aparece.

Tudo parece indicar que a dimensão do conflito desloca-se para outros pontos. Então estamos falando de um sujeito não referido em um espaço e um tempo, dimensōes estas essenciais ao que chamamos de subjetividade atualmente. O espaço registra a existência , o limite e o tempo a história, a morte, a finitude. Na medida em que a vida é coisificada em um objeto-brinquedo (vide brinquedos que são alimentados,choram e etc..) e que atribuímos personalidade aos computadores nos relacionando como que com outros seres humanos, estas dimensões estão se esgotando, e outras formas se organizarão. Sujeitos sem tempo, sem história, fabricados por um espaço virtual mais do que fabricando este espaço. Ficaríamos sem saber se cada um de nós é virtual, pois podemos criar antepassados, imaginar e criar pessoas de outro tempo e espaço, mortas anteriormente seja pela sua insuficiência biológica, seja pela palavra.

A virtualidade afeta hoje não apenas a informação e a comunicação, mas também os corpos, o funcionamento econômico, os quadros coletivos da sensibilidade ou o exercício da inteligência (Levy, 1996). Dessa forma, produz um sujeito com sua vida introduzida na ilusão de um certo tempo e espaço onde tudo é possível. Mediatizado pelo computador ou imagem virtual de mim mesmo, um novo laço entre o "eu" e o "outro" parece se constituir. Despreza-se, repetidamente, aquilo que podemos chamar dos encontros entre os indivíduos, conduzidos na esfera da realidade cotidiana, e sustentados por embates de imagens, de palavras, de olhares e de sensaçōes, característicos do espaço público. A ilusão de auto-suficiência ou do "eu autônomo", em parte produzida por algumas idéias psicológicas de necessidade de interiorização ou de auto-conhecimento, embuste de uma verdadeira roupagem narcísica, provoca um desligamento do espaço coletivo, observado aliás em certos grupos de crianças e adolescentes.

As relações mediatizadas não mais pela palavra conjugada com a imagem mas, sobretudo, pela imagem desencarnada da palavra e da sensação do outro diante de si (vide internet) parece indicar vetores subjetivos que rompem por completo as nossas construções históricas e psíquicas, tão enraizadas em lembranças repletas de sensações, sejam olfativas, visuais, táteis, gustativas e auditivas, sejam impregnadas de sentidos produzidos. 
Talvez, por hipótese, estejamos caminhando para uma tentativa de minimização do espaço relacional, ou melhor, na busca de um espaço onde cada um relaciona-se com aquilo que quer imaginar a respeito do outro. Inflação imaginária, sem dúvida, narcisismo supradimensionado, ainda mais.

Deste modo, estas questões em tempos virtuais, nos levam a pensar para além do subjetivo, no aspecto sócio-político, ou seja, compreender o movimento contemporâneo para termos chance de nos tornarmos atores dele, pois todas estas estratégias brecam os processos de subjetivação e impossibilitam a vida. E aqui chegamos a uma nova empreitada (um novo texto, talvez): subjetividade, cultura e ética.
Guattari, F (1992) Caosmose: um novo paradigma estético. Rio de Janeiro: Editora 34.

Levy, P. (1996) O que éo virtual? São Paulo: Editora 34.
Aragão, L.T. de (1991) Clínica do social: ensaios, São Paulo:Escuta.

Lins, D.S. (1997) Cultura e subjetividade: saberes nômades. São Paulo: Papirus.
Referências bibliográficas

Lacan, J. (1986) Os Escritos Técnicos de Freud (1953/1954). Rio de Janeiro: Zahar 